\title{
Histomorphological Analysis of Lesions In Nephrectomy Specimens: A 4 Years Study In A Rural Hospital In India-Our Experience
}

\author{
Kishor H. Suryawanshi ${ }^{1 *}$, Rajshri P. Damle ${ }^{1}$, N.V.Dravid ${ }^{1}$, Ashish Patil Rawandale ${ }^{2}$ and Akshay Surana ${ }^{1}$ \\ ${ }^{1}$ Department Of Pathology, A.C.P.M. Medical College, Dhule, Maharashtra. India. \\ ${ }^{2}$ Department of Urology, A.C.P.M. Medical College, Dhule, Maharashtra. India.
}

\begin{abstract}
Background: Kidney is involved in various pathological conditions ranging from non-neoplastic lesions to neoplastic diseases like renal cell carcinoma. Nephrectomy remains the treatment of choice for patient care in end stage renal diseases from various causes and neoplastic lesions.
\end{abstract}

Objective: To study the histomorphological spectrum and frequency of various lesions in nephrectomy specimens.

Methods: A observational retrospective research study included 33 nephrectomy specimens in the department of pathology over a period of 4 years (April 2012 to April 2016).Clinical details and radiological findings were noted from records and clinico-histomorphological correlation was done.

Results: A total of 33 nephrectomy specimens were studied. Age distribution varied from 16 to 71 years with male to female ratio of 2:1.Benign lesions comprised of maximum cases (75.76\%) while malignant lesion were present in $24.24 \%$ cases. Chronic nonspecific pyelonephritis was the predominant non-neoplastic finding followed by xanthogranulomatous pyelonephritis. Renal cell carcinoma was the most common malignant lesion in this study.

Conclusion: Chronic nonspecific pyelonephritis leading to end stage renal disease is the commonest causative factor in our region ; may be due to consumption of hard water in rural areas.

Keywords: Chronic Nonspecific Pyelonephritis, End Stage Renal Disease, Nephrectomy

\section{Introduction:}

Kidney plays a vital role in excretion of waste product, water and electrolyte metabolism along with acid base balance, maintenance of blood pressure by secretion of renin-angiotensin and regulation of erythropoiesis by erythropoietin. Renal diseases are responsible for great deal of morbidity than mortality. Nephrectomy in the form of partial or radical is now-a-days became a common procedure in surgical and urological practice. Simple nephrectomy is indicated in patients with traumatic injury, end stage renal diseases resulting from obstructive uropathy, calculus disease, renovascular hypertension, chronic urinary tract infections and renal dysplasia. An indication of nephrectomy depends on the type of lesion, extent of damage, general condition of patient and status of contralateral kidney. ${ }^{[1,2]}$ Moreover gold standard treatment renal tumors is radical or partial nephrectomy. ${ }^{[3]}$

\section{Material and methods}

This study was a observational retrospective research study conducted in Department of Pathology from April 2012 to April 2016 and included 33 nephrectomies specimen from patients presented to Surgery/Urology department. Patients presented with complaints of hematuria, dysuria, loin pain, anuria and pyuria to Surgery /Urology department. Detail clinical history, significant findings, radiological findings were noted from records. All nephrectomies specimen were studied with clinical features, radiological findings, gross and microscopic findings. Representative sections were processed by paraffin embedding, stained with Haematoxylin and eosin stain. Special stains and immunohistochemistry were done wherever necessary. A final histopathological diagnosis was made with clinical and radiological correlations. The research study has been approved by ethical committee.

\section{Results}

The present study included 33 cases of nephrectomies specimen from patients presented to Surgery and Urology department. Age group of patients ranged from 16 years to 71 years. Maximum no. of patients were in the age group of $31-40$ years $(24.24 \%)$ followed by $41-50$ years $(24.24 \%)$. [Table 2] Out of 33 patients 22(66.67\%) were males and 
11(33.33\%) were females. Male to female ratio was 2:1. [Table 1] A greater percentage of both benign lesions $(51.52 \%)$ and malignant lesions $(15.15 \%)$ were observed in males as compared to females. Histomorphological distribution of lesions [Table-3] showed that chronic nonspecific pyelonephritis $(51.51 \%)$ [Fig.1a] was the commonest finding followed by renal cell carcinoma in 8 cases $(24.24 \%)$ and xanthogranulomatous pyelonephritis in 6 cases (18.18\%)[Fig.1b].Age wise distribution of lesions [Table-4] showed that maximum number of cases of chronic nonspecific pyelonephritis were observed in 21-40 yrs age group while renal cell carcinoma was predominant in the age group of 41-60 yrs. Benign lesions(75.76\%) comprised maximum number of cases while malignant lesions were observed in $24.24 \%$ cases. The most common clinical presentation was loin pain followed by dysuria, hematuria, pyuria, fever and abdominal lump in three cases.

The commonest clinical diagnosis made was nonfunctioning kidney in 21 cases $(63.63 \%)$ based on clinical and radiological findings. In 10 cases renal cell carcinoma was suspected based on radiological finding of renal mass. Out of 8 cases of RCC, 4 were clear cell type, 2 were papillary type and 1 case each of chromophobe RCC and collecting duct RCC was reported.[Fig.2-a,b,c,d]. One case was reported as multicystic nephroma.[Fig.1c \& 1d]

Table 1: Sex wise distribution of benign \& malignant lesions [Cases=33]

\begin{tabular}{|c|c|c|c|}
\hline Lesions & Males & Females & Total \\
\hline Benign & $17(51.52 \%)$ & $08(24.24 \%)$ & $75.76 \%$ \\
\hline Malignant & $05(15.15 \%)$ & $03(9.09 \%)$ & $24.24 \%$ \\
\hline Total & $\mathbf{2 2 ( 6 6 . 6 7 \% )}$ & $\mathbf{1 1 ( 3 3 . 3 3 \% )}$ & $100 \%$ \\
\hline
\end{tabular}

Table 2: Age-wise distribution of nephrectomy specimens

\begin{tabular}{|c|c|c|}
\hline Age group(yrs) & No. of cases & \% \\
\hline $0-10$ & 0 & 12.12 \\
\hline $11-20$ & 4 & 9.09 \\
\hline $21-30$ & 3 & 24.24 \\
\hline $31-40$ & 8 & 24.24 \\
\hline $41-50$ & 8 & 18.18 \\
\hline $51-60$ & 6 & 9.09 \\
\hline $61-70$ & 3 & 3.03 \\
\hline
\end{tabular}

Table 3: Gender wise distribution of histopathological lesions

\begin{tabular}{|l|c|c|c|}
\hline Lesion & No. of cases & Male & Female \\
\hline Chronic nonspecific pyelonephritis & 17 & 04 & 06 \\
\hline Xanthogranulomatous pyelonephritis & 06 & 05 & 03 \\
\hline Renal cell carcinoma & 08 & 01 & 00 \\
\hline Multicystic nephroma & 01 & 01 & 00 \\
\hline $\begin{array}{l}\text { Severe hydronephrosis with secondary } \\
\text { atrophy of renal parenchyma }\end{array}$ & 01 & & 0 \\
\hline
\end{tabular}

Table 4: Age wise distribution of histopathological lesions

\begin{tabular}{|c|c|c|c|c|}
\hline Lesions & $0-20$ yrs & $21-40$ yrs & $41-60$ yrs & $61-70$ yrs \\
\hline Chronic nonspecific pyelonephritis & 3 & 7 & 6 & 1 \\
\hline Xanthogranulomatous pyelonephritis & 0 & 2 & 2 & 2 \\
\hline Renal cell carcinoma & 0 & 2 & 5 & 1 \\
\hline Multicystic nephroma & 0 & 0 & 1 & 0 \\
\hline $\begin{array}{l}\text { Severe hydronephrosis with secondary } \\
\text { atrophy of renal parenchyma }\end{array}$ & 1 & 0 & 0 & 0 \\
\hline
\end{tabular}


Table 5: Sex wise distribution of RCC.

\begin{tabular}{|c|c|c|c|}
\hline Types of RCC & No. of cases & Male & Female \\
\hline Clear cell RCC & 04 & 03 & 01 \\
\hline Papillary RCC & 02 & 01 & 01 \\
\hline Chromophobe RCC & 01 & 01 & -- \\
\hline Collecting duct RCC & 01 & -- & 01 \\
\hline
\end{tabular}

Table 6: Comparison of Incidence of benign \& malignant lesions in various studies.

\begin{tabular}{|c|c|c|}
\hline Author study & Benign lesions (\%) & Malignant lesions (\%) \\
\hline${\text { Ghalayaini(2002) })^{[12]}}^{[2]}$ & 70.44 & 29.5 \\
\hline Rafique(2007) $)^{[5]}$ & 76.6 & 23.4 \\
\hline Mahesh KU(2012) ${ }^{[1]}$ & 54.54 & 45.45 \\
\hline Aiman et al (2013) ${ }^{[7]}$ & 77.2 & 22.8 \\
\hline Present study(2015) & 75.76 & 24.24 \\
\hline
\end{tabular}

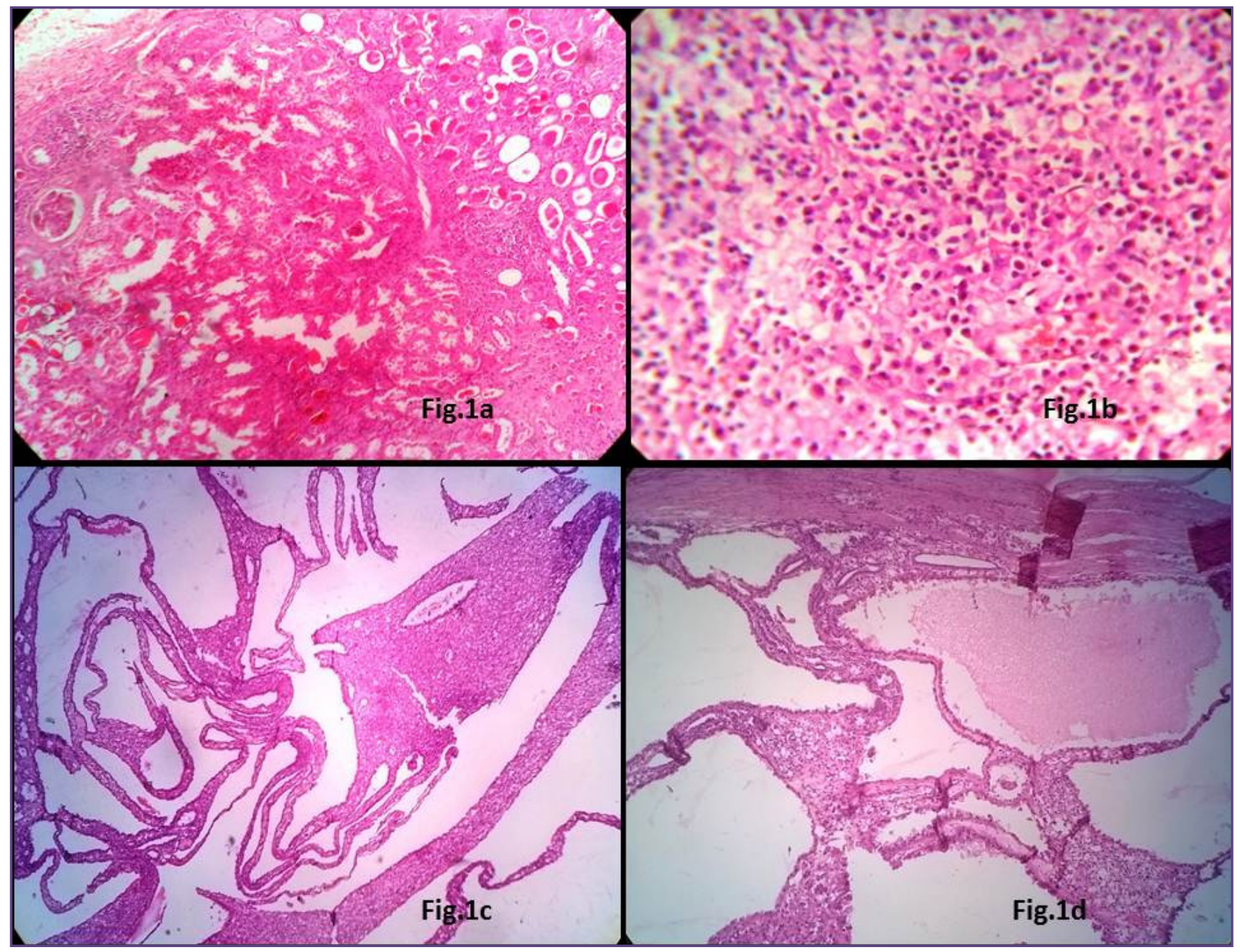

Fig. 1: (a) Chronic non-specific pyelonephritis (H\&E; x100) ;( b) Xanthogranulomatous pyelonephritis (H\&E; x100) ;(c) Multicystic nephroma (H\&E; x100) and (d) Multicystic nephroma (H\&E; x400). 


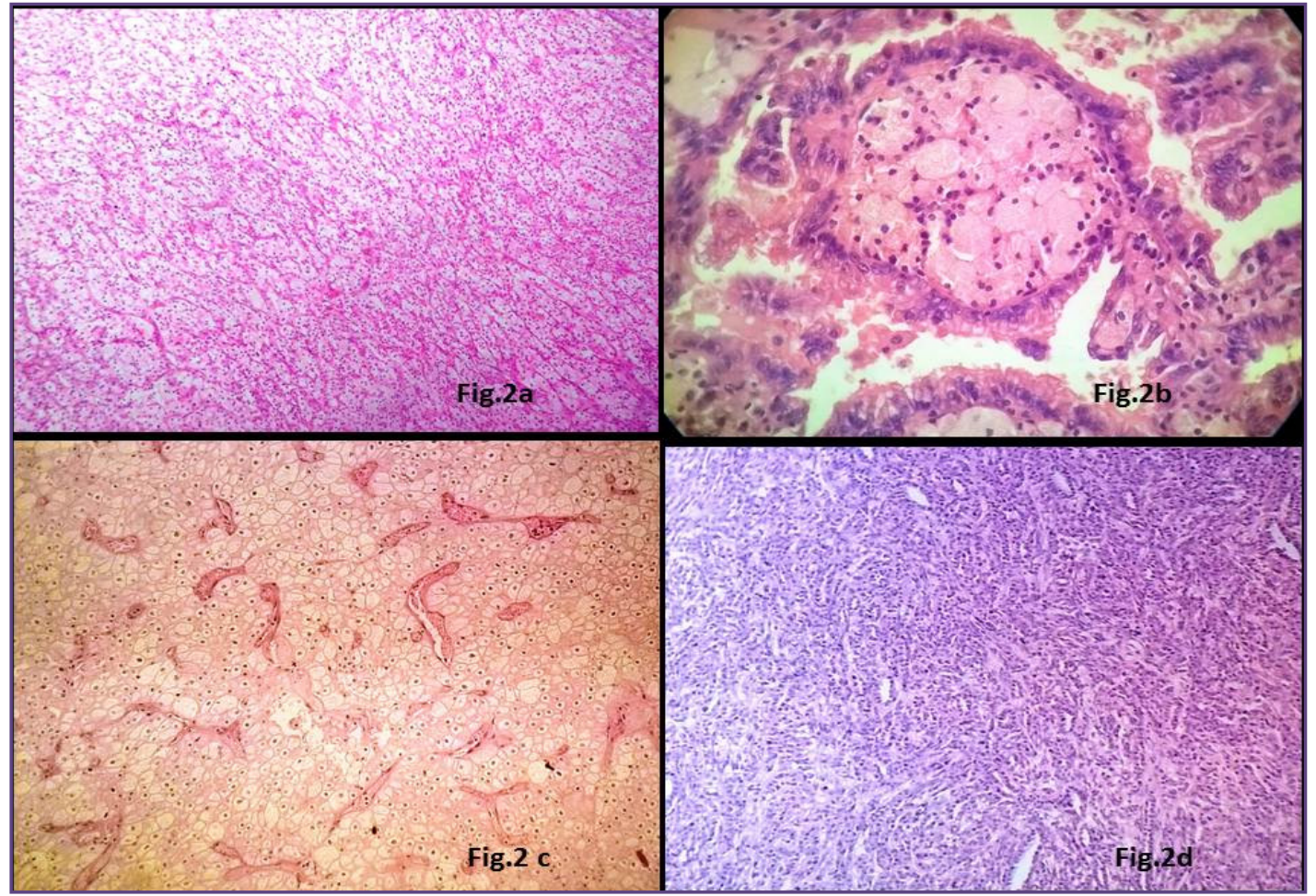

Fig. 2: (a) RCC ; clear cell type (H\&E; x100) ; (b) RCC ; papillary type (H\&E; x400) ;(c) RCC ; chromophobe pattern (H\&E; x400) and (d) RCC ; collecting duct type (H\&E; x100).

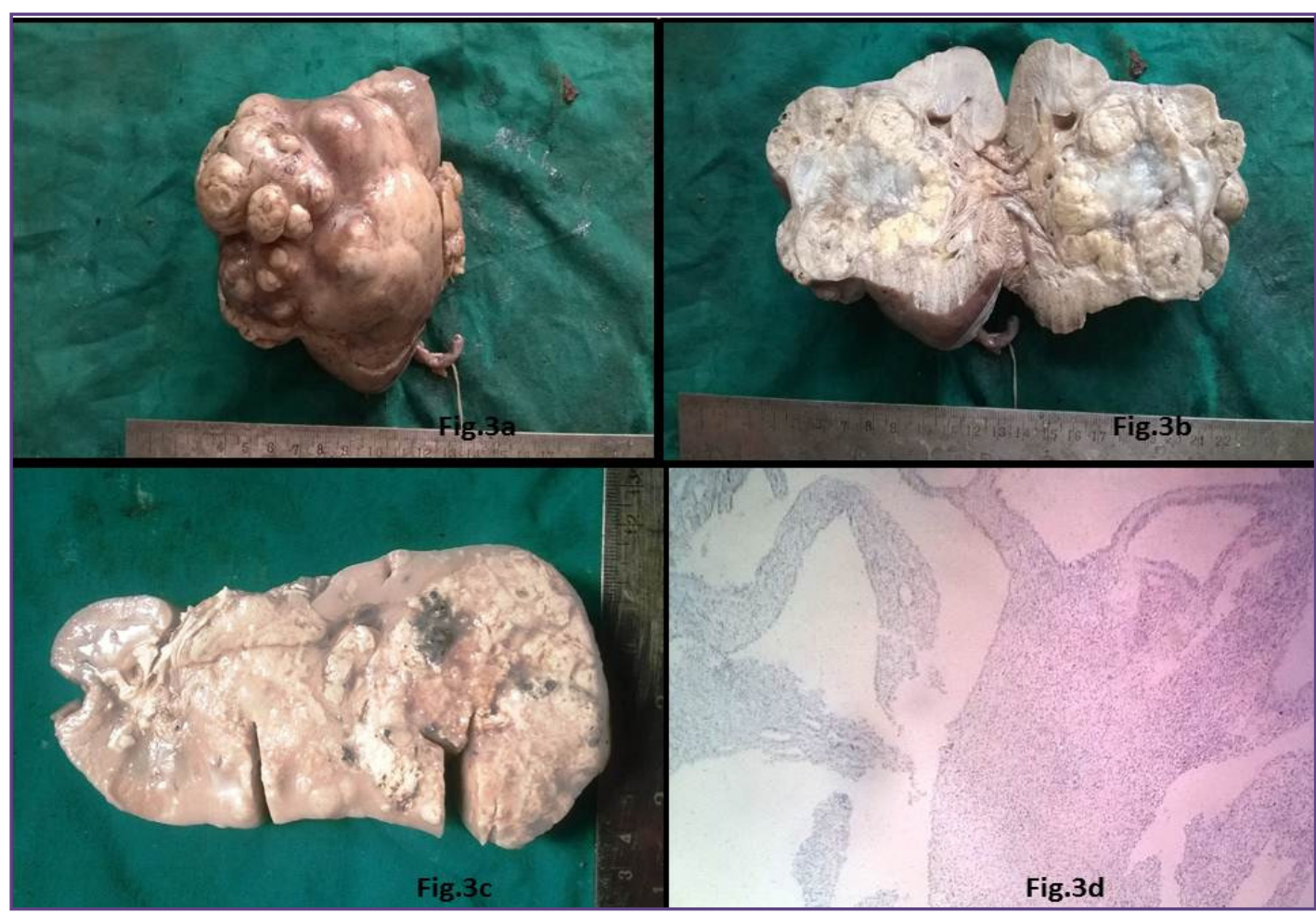

Fig 3: (a) Gross photograph-External surface showed enlarged kidney with bosselated surface and varying size nodules. (b)\&(c) RCC- cut surface showed variegated appearance with areas of necrosis and hemorrhage.(d) Multicystic nephroma showed immunopositivity for Pax 8 .(d). 


\section{Discussion}

Gustav Simon, in 1869 and 1870, performed planned nephrectomy for urinary fistula and partial nephrectomy for hydronephrosis respectively. ${ }^{[4]}$ Kidney is involved in variety of pathological conditions ranging from nonneoplastic to neoplastic lesions. Indications of nephrectomy depend on the type of lesion, extent of damage, general condition of patient and status of contralateral kidney.

The present study included 33 nephrectomies specimen. Age group of patients ranged from 16 to 71 years with male to female ratio of 2:1.Similar results of male preponderance were observed by Rafique et $\mathrm{al}^{[5]}$ and $\mathrm{El}$ Malik et a ${ }^{[6]}$. Aiman et al ${ }^{[7]}$ reported female preponderance in their study.

The highest percentage of patient [24.24\%] were from $3^{\text {rd }}$ decade and $4^{\text {th }}$ decade which was in concordance with Rafique et al ${ }^{[5]}$. Loin pain followed by dysuria, hematuria, fever were commonest symptoms of patients in this study. Lump in abdomen was present in 3 cases who were later on diagnosed as cases of renal cell carcinoma [RCC] histopathologically.

Out of 25 benign lesions chronic nonspecific pyelonephritis [CPN] was the predominant finding observed in 17 cases; xanthogranulomatous pyelonephritis [XGPN] in 6 cases; severe hydronephrosis and multicystic nephroma in one case each. Maximum no. of cases of CPN and XGPN were seen in 21-40 years. 2 cases of XGPN and 4 cases of chronic pyelonephritis were associated with renal calculus disease. Huland $\mathrm{H}^{[8]}$ in his series reported 161 patients of end stage renal disease with 42 patients (26\%) had chronic pyelonephritis with bacteriuria in the past. All benign lesions were observed predominantly in males as compared to females. In the present study it is observed that RCC comprised all cases of malignant lesions. All malignant lesions were confirmed histopathologically as renal cell carcinoma with subtypes- 4 cases of clear cell type; 2 cases of papillary type and one case of each chromophobe RCC and collecting duct RCC. Amongst 8 cases of RCC, 4 cases of clear cell RCC showed Fuhrman's nuclear grade 2, 2 cases of papillary RCC showed low nuclear features. Similar experience finding of RCC as predominant malignant lesion were reported by Rafique et $\mathrm{al}^{[5]}$ and Popat et al ${ }^{[9]}$. Out of 8 cases of RCC 5 were found in males and 3 were in females.[Table-5] 5 cases were found in the age group 41-60 years; 2 cases in 21-40 years and one case in 61-70 years.

Grossly majority cases (4) of RCC were found in left kidney with upper pole involvement in 4 cases. Five cases showed variegated appearance with areas of necrosis and hemorrhage. [Fig. 3b\&3c] One case of cystic mass in kidney suspected as RCC clinically was diagnosed as multicystic nephroma histopathologically and confirmed by immunohistochemistry study. It showed immunopositivity for Pax 8[Fig. 3d] and immunonegativity for p63/CD30. Multicystic nephroma is a rare benign lesion of kidney with bimodal age distribution. Adult onset multicystic nephoma is more common in postmenopausal females. In our case patient was a elderly male. Two cases of XGPN in older age group were suspected clinically as well as on grossly as RCC were confirmed as XGPN on histomorphology. In the present study out of 6 cases of XGPN 4 were seen in males due to calculus disease and 2 in females were associated with recurrent urinary tract infection. In the present study predominant cause of nephrectomy was non neoplastic lesions [75.76\%] of kidney while neoplastic lesions with RCC as predominant lesion included only $24.24 \%$. Geographical variation is found in indications of nephrectomy from review of literature. Study from Norway ${ }^{[10]}$ and Nigeria ${ }^{[1]}$ reported $68 \%$ and $67 \%$ respectively as a rate of nephrectomy for malignant lesions. Renal tuberculosis as a cause of nephrectomy was reported in $2.4 \%$ and $7.6 \%$ cases by Beisland et $\mathrm{al}^{[10]}$ and Rafique et al ${ }^{[5]}$ respectively. Renal tuberculosis is common in developing countries as compared to developed countries and patients present with sterile pyuria. But in our study we could not find renal tuberculosis as a cause of nephrectomy.

While analyzing cause of end stage renal disease or non-functioning kidney from patients clinical details, radiological and histopathological findings, it was observed that calculus renal disease was the predominant cause of ESRD in our region. This may be due to consumption of hard drinking water in large area in rural population in our region. So education and screening programs are needed in such population to reduce rate of nephrectomy due to nonneoplastic lesions especially calculus renal disease.

In comparison to various studies in the literature our findings were similar to findings of Ghalyaini et $\mathrm{a}^{[12]}$, Rafique et al and Aiman et al. Mahesh KU et a ${ }^{[1]}$ reported neoplastic lesions $(54.5 \%)$ as the predominant cause of nephrectomy in his study. Ghalyaini et al ${ }^{[12]}$ reported youngest patient of 7-year-old child with RCC in his series.

\section{Conclusion}

To conclude, non-neoplastic lesions of kidney comprised the most common lesions in nephrectomy specimen. RCC was the most common malignant lesion with clear cell RCC as the most common subtype. 


\section{References}

1. Mahesh KU, Yelikar BR,Patil G, Karigoudar MH, Pande P,Patil SB. Spectrum of Histopathological lesions in Nephrectomy specimens - A two year study in a tertiary care hospital. Int J of Research in Pharmaceutical and Biomedical Sciences 2012;3(4):1787-90.

2. Divyashree BN, Venkatesh K, Madhusudhan HR, Hanumantha Raju BK. "Pathological Spectrum of NonNeoplastic Diseases in the Nephrectomy Specimens". Journal of Evidence based Medicine and Healthcare 2014; 1(15): 1909-1920.

3. Algaba F, Trias I, Scarpelli M, Boccon-Gibod L, Kirkali Z, Poppel HV. Handling and pathology reporting of renal tumor specimens. Eur Urol 2004;45: 437-43

4. Harry W. Herr. A history of partial nephrectomy for renal tumours. J Urol. 2005; 173(3): 705-708.

5. Rafique M. Nephrectomy: Indications, complications and mortality in 154 consecutive patients. J Pak Med Assoc 2007;57:308-11.
6. El Malik EM, Memon SR, Ibrahim AL, Al Gizawi A, Ghali AM. Nephrectomy in Adults: Asir Hospital Experience. Saudi J Kidney Dis Transpl 1997;8:423-7.

7. Aiman A, Singh K, Yasir M. Histopathological spectrum of lesions in nephrectomy specimens: A five-year experience in a tertiary care hospital. J Sci Soc 2013;40:148-54.

8. Huland H, Busch R. Chronic pyelonephritis as a cause of end stage renal disease. J Urol 1982;127:642-3.

9. Popat VC, Kumar MP, Udani D, Mundra MP, Vora DN, Porecha MM. A study on culprit factors ultimately demanding nephrectomy. Internet J Urol 2010;7.

10. Beisland C, Medby PC, Sander S, Beisland HO. Nephrectomy indications, complications and post-operative mortality in 646 consecutives patients. Eur Urol 2000;37:58-64.

11. Eke N, Echem RC. Nephrectomy at the University of Port Harcourt Teaching Hospital: a ten year experience. Afr J Med Sci 2003;32:173-77.

12. Ghalayini IF. Pathological spectrum of nephrectomies in a general hospital. Asian J Surg 2002;25:163-9.

*Corresponding author:

Dr. Suryawanshi Kishor H. Department Of Pathology, A.C.P.M.Medical College, Dhule, Maharashtra. India. 424005

Phone: +91 9403424244

Email: ompathologylab@gmail.com

Date of Submission : 13.10.2016

Date of Acceptance : 13.02.2017

Financial or other Competing Interests: None.

Date of Publication : 04.06.2017 